\title{
Synthesis and Characterization of Benzimidazole by Using o-Phenylenediamine with Different Aldehydes and Carboxylic Acids in the Presence of $\rho-\mathrm{T}_{\mathrm{s}} \mathrm{OH}$ as a Catalyst
}

\author{
ABDULLAH JAWAD KADHIM ${ }^{1 *}$ and ALI CHAZI KAZIM ${ }^{2}$ \\ 1,2University of Al-Qadisiyah, College of Education, Chemistry department, Iraq. \\ *Correponding auhtor E-mail: abdullah.kadhim @ qu.edu.iq \\ http://dx.doi.org/10.13005/ojc/3404054
}

(Received: March 23, 2018; Accepted: May 27, 2018)

\begin{abstract}
This research paper deals with the synthesis and diagnose of Benzimidazole rings which were have been prepared by using two different methods in which used starting material o-phenylenediamine with different compounds. The first method is with aldehydes such as 4-Chlorobenzaldehyde, 4-N, N-Dimethylbenzaldehyde, and Formaldehyde. The second is with carboxylic acids such as salicylic acid, acetic acid, and butanoic acid. $\rho-\mathrm{T}_{s} \mathrm{OH}$ has been using as a catalyst in the synthesis methods above and used F.T.I.R and HNMR spectroscopy are used for diagnosing the prepared rings in addition to the physical properties.
\end{abstract}

Keywords: Aldehydes, Benzimidazole, Carboxylic Acids, $\rho$-(Tolune sulphonic acid ).

\section{INTRODUCTION}

Benzimidazole is one of the heterocyclic compounds that shows different biological qualities such as antibacterial and antifungal ${ }^{1}$. Also, some Benzimidazoles have an effect on human viruses such as cytomegalovirus ${ }^{2}$. There are two procedures for the synthesis of 2-substituted Benzimidazoles. The first is the reaction of phenylenediamines and carboxylic acids or its derivatives by heating ${ }^{3}$ in strong drying conditions ${ }^{4}$. The second includes a two-step procedure that includes the oxidative cyclodehydrogenation of Schiff bases, which are often generated from the condensation of phenylenediamines and aldehydes ${ }^{3}$ and with aryl-aldehydes by using an acidic agent and also with silica gel at room temperature ${ }^{4}$. $\rho-\mathrm{TsOH}$ has been used as a neutral acid catalyst to synthesize a number of benzimidazoles ${ }^{5}$. It is considered as an important, effective, available and inexpensive incentive ${ }^{6}$. Also, there are many ways to synthesize benzimidazole by using different catalysts such as Nanocrystalline oxides with iodine ${ }^{7}$, $\mathrm{H}_{2} \mathrm{O}_{2} / \mathrm{HCl}$ and $\mathrm{Cu}(\mathrm{OTf})_{2}{ }_{2}^{8}, \mathrm{HCl}^{9}$. In this work, the aim was the synthesis of benzimidazole rings by using one catalyst is $\rho$-TsOH as in previous studies above, which have used one catalyst in different circumstances.

This is an Open Access article licensed under a Creative Commons Attribution-Non Commercial-Share Alike 4.0 International License (https://creativecommons.org/licenses/by-nc-sa/4.0/), which permits unrestricted Non Commercial use, distribution and reproduction in any medium, provided the original work is properly cited. 


\section{Instruments}

1- $\quad$ Melting points have been determined by using Melting pointSMP3 apparatus.

2- $\quad$ F.T.I.R spectra have been recorded by using Fourier Transform Infrared Spectrophotometre (F.T.I.R) 8400 S Shimadzu apparatus.

3- $\quad$ HNMR spectra have been recorded by using NMR Spectrometer 400 MHz, Avance III 400 Bruker, Germany.

4- U.V. spectra have been recorded by using U.V-Visible Spectrophotometer 1650 PC Shimadzu apparatus.

\section{EXPERIMENTAL}

The General Method for Synthesizing Benzimidazoles from Aldehydes

A solution of Aldehyde (0.01 mole), o-phenylenediamine $(0.01 \mathrm{~mol})$ and DMF $(3 \mathrm{ml})$ has been mixed with $\rho$-TsOH $(20 \mathrm{ml})$. The mixture has been heated and stirred at $80 \mathrm{C}^{\circ}$ for $2-3 \mathrm{~h}$ then cooled to reach room temperature, the mixture has been added dropwise with stirring into mixture of $\mathrm{Na}_{2} \mathrm{CO}_{3}$ $(0,01 \mathrm{~mole})$ and $\mathrm{H}_{2} \mathrm{O}(20 \mathrm{ml})$, the product has been filtered, washed by $\mathrm{H}_{2} \mathrm{O}$, then dried ${ }^{2}$ to yield $\mathrm{A}, \mathrm{B}$ and C compounds.

The General Method for Synthesizing Benzimidazole from Carboxylic Acids

A solution of Carboxylic acid ( 0.01 mole), o-phenylenediamine $(0.01 \mathrm{~mole})$ and toluene $(10 \mathrm{ml})$ has been mixed with $\rho-\mathrm{TsOH}(20 \mathrm{ml})$. The mixture has been refluxed for 2-3 $\mathrm{h}$ then cooled, filtered and dried $^{10}$ to yield $D, E$ and $F$ compounds.

\section{RESULT AND DISCUSSION}

Synthesis compounds characterized by F.T.I.R. and H-NMR spectroscopy have showed an important absorption packs of functional groups for the synthesis Benzimidazole derivatives from aldehydes and carboxylic acids with presence of $\rho-\mathrm{T}_{S} \mathrm{OH}$ as a catalyst in the different conditions.

\section{2-(4-Chlorophenyl) -1H-Benzimidazole (A)}

The F.T.I.R spectrum of this compound shows appearance of an absorption pack at $3379 \mathrm{~cm}^{-1}$ refers to $(\mathrm{N}-\mathrm{H})$ group and appearance of an absorption pack at $686 \mathrm{~cm}^{-1}$ refers to $(\mathrm{C}-\mathrm{Cl})$ bond. HNMR (400 MHz) $\delta(p p m)$ Benzi. (7.26t 2H) and (7.71t 2H), Ar (7.31 and 7.61), N-H(3.42s). Table (2) shows the other absorption packs of the compound in the F.T.I.R spectrum.

\section{2-(4-N,N- Dimethylaniline)-1 H-Benzimidazole (B)}

The F.T.I.R spectrum of this compound shows an absorption pack at $3301 \mathrm{~cm}^{-1}$ refers to $(\mathrm{N}-\mathrm{H})$ group and appearance of an absorption pack at $2916 \mathrm{~cm}^{-1}$ refers to $(\mathrm{C}-\mathrm{H})$ aliphatic. $\mathrm{H}-\mathrm{NMR}$ (400 MHz) $\delta(\mathrm{ppm}) \operatorname{Ar}(6.91$ and 7.31), Benzi. (7, 26t 2H 7.69t 2H), N-H(4.42d), $\mathrm{CH}_{3}$ (2.91). Table (2) shows the other absorption packs of the compound in the F.T.I.R spectrum.

\section{H-Benzimidazole (C)}

The F.T.I.R spectrum of this compound shows an absorption pack at $3409 \mathrm{~cm}^{-1}$ refers to $(\mathrm{N}-\mathrm{H})$ group and an absorption pack at $2923 \mathrm{~cm}^{-1}$ refers to $(\mathrm{C}-\mathrm{H})$ aliphatic. $\mathrm{HNMR}(400 \mathrm{MHz}) \delta(\mathrm{ppm})$ Benzi. (7.68t 2H) and (7.26-7.30t 2H), N-H(2.9Hz), Benz.- $\mathrm{CH}(7.90 \mathrm{~Hz})$. Table (2) shows the other absorption packs of the compound in the F.T.I.R spectrum.

\section{2-(2-hydroxy phenyl)-1H-Benzimidazole (D)}

F.T.I.R spectrum of this compound shows an absorption pack at $3425 \mathrm{~cm}^{-1}$ refers to $(\mathrm{O}-\mathrm{H})$ group

Table 1: Physical Properties of Compounds

\begin{tabular}{cccccc}
\hline Compounds & Molecular formula & Solvent & Yield \% & m. p. Co & Color \\
\hline A & $\mathrm{C}_{13} \mathrm{H}_{9} \mathrm{~N}_{2} \mathrm{Cl}$ & DMF & 78 & $294-298$ & Brown \\
B & $\mathrm{C}_{15} \mathrm{H}_{15} \mathrm{~N}_{3}$ & DMF & 72 & $237-240$ & Nutty \\
C & $\mathrm{C}_{6} \mathrm{H}_{6} \mathrm{~N}_{2}$ & DMF & 85 & $115-118$ & Yellow \\
D & $\mathrm{C}_{13} \mathrm{H}_{10} \mathrm{~N}_{2} \mathrm{O}$ & Toluene & 81 & $151-157$ & Yellow \\
E & $\mathrm{C}_{8} \mathrm{H}_{8} \mathrm{~N}_{2}$ & Toluene & 72 & Oil & Nutty \\
F & $\mathrm{C}_{10} \mathrm{H}_{12} \mathrm{~N}_{2}$ & Toluene & 68 & 249 dec. & Nutty \\
\hline
\end{tabular}


and appearance of an absorption pack at $1157 \mathrm{~cm}^{-1}$ refers to (C-O) bond in addition to an absorption pack $(\mathrm{N}-\mathrm{H})$ group at $3240 \mathrm{~cm}^{-1}$. HNMR $(400 \mathrm{MHz}) \delta(\mathrm{ppm})$
Benz. (7.26t 2H) and (7.75t 2H), Ar (7.35-7.00), $\mathrm{N}-\mathrm{H}(2,93 \mathrm{~s}), \mathrm{O}-\mathrm{H}(7.97)$. Table (2) shows the other absorption packs of compound in F.T.I.R spectrum.

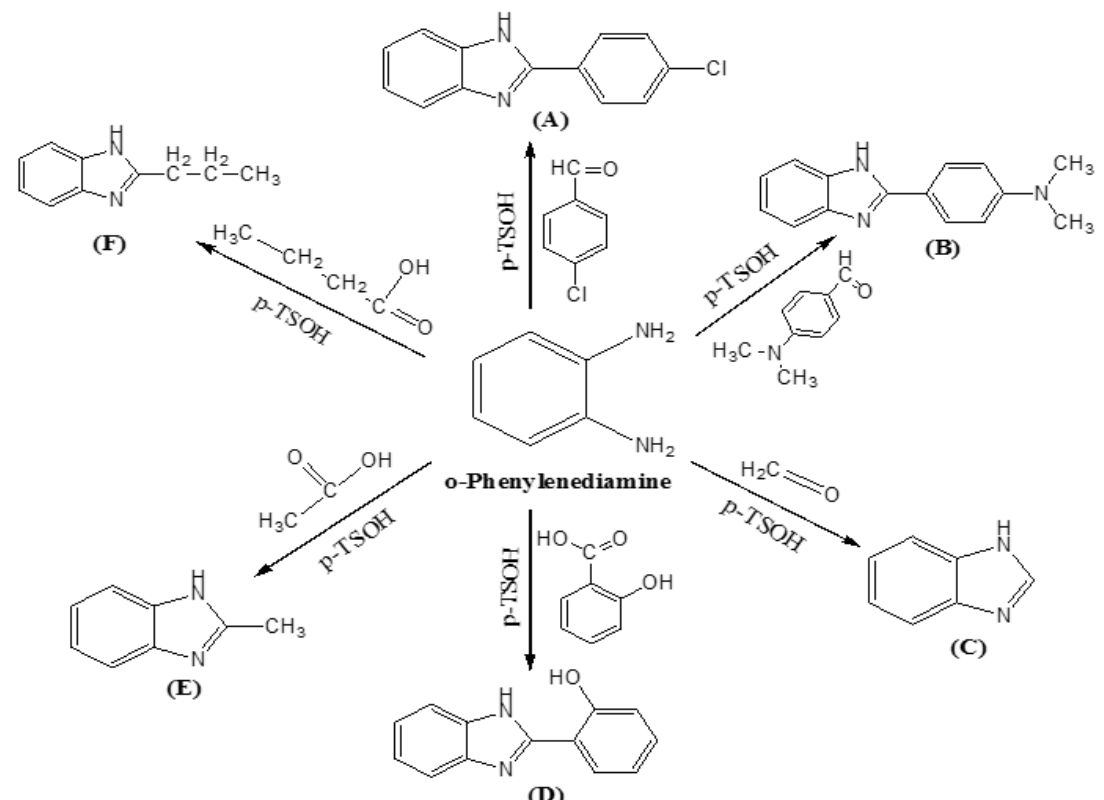

(D)

\section{2-Methyl-1H-Benzimidazole (E)}

The F.T.I.R spectrum of this compound shows an absorption pack at $3178 \mathrm{~cm}^{-1}$ refers to $(\mathrm{N}-\mathrm{H})$ group and an absorption pack at $2916 \mathrm{~cm}^{-1}$ refers to $(\mathrm{C}-\mathrm{H})$ aliphatic. HNMR $(400 \mathrm{MHz}) \delta(\mathrm{ppm})$ Benz. (7.26t $2 \mathrm{H}$ and 7.71t $2 \mathrm{H}), \mathrm{N}-\mathrm{H}(2.45), \mathrm{CH}_{3}$ (2.20s). Table (2) shows the other absorption packs of the compound in the F.T.I.R spectrum.
2-Propyl-1H-Benzimidazole (F)

The F.T.I.R spectrum of this compound shows an absorption pack at $3209 \mathrm{~cm}^{-1}$ refers to $(\mathrm{N}-\mathrm{H})$ group and an absorption pack at 2962 and $2931 \mathrm{~cm}^{-1}$ to $(\mathrm{C}-\mathrm{H})$ aliphatic. HNMR $(400 \mathrm{MHz})$ $\delta(\mathrm{ppm})$ Benz. (7.29t $2 \mathrm{H})$ and $(7.71 \mathrm{t} 2 \mathrm{H}), \mathrm{N}-\mathrm{H}(4.28 \mathrm{~s})$, $-\mathrm{CH}_{2}-\mathrm{CH}_{2}(2.42 \mathrm{~S}), \mathrm{CH}_{2}-\mathrm{CH}_{2}-(1,43 \mathrm{~S}), \mathrm{CH}_{3}(0.92 \mathrm{~S})$. Table (2) shows the other absorption packs of the compound in the F.T.I.R spectrum.

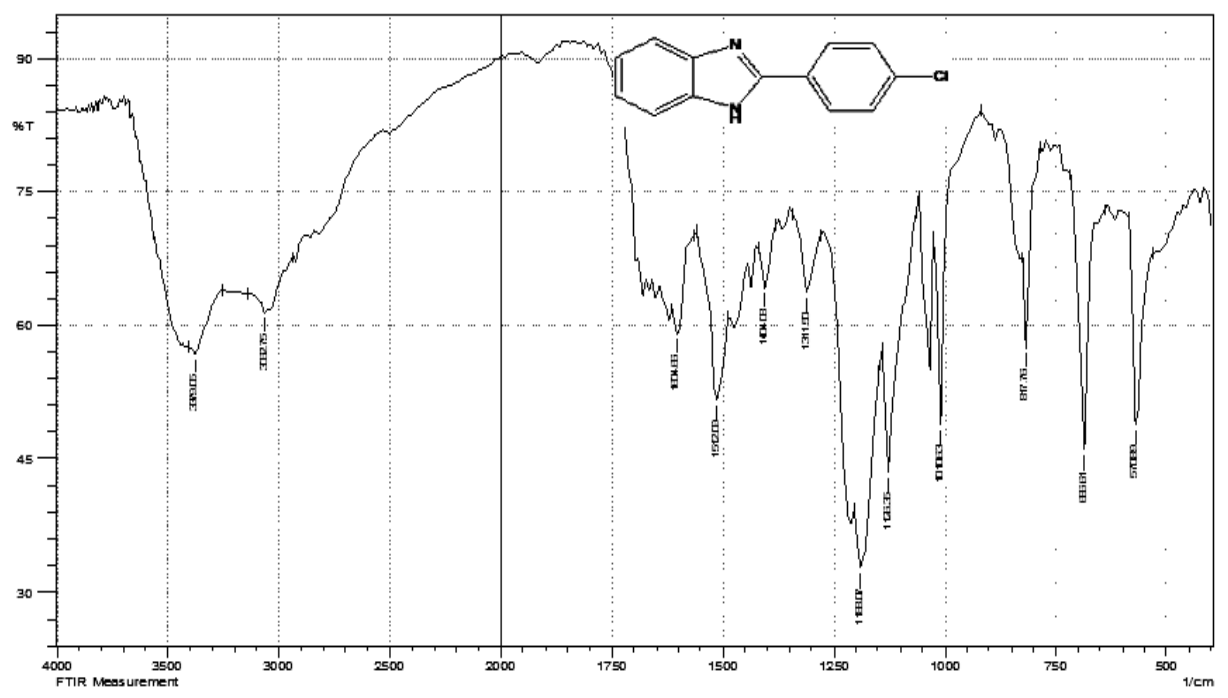

Fig. 1. (F.T.I.R) Spectrum of Compound(A) 


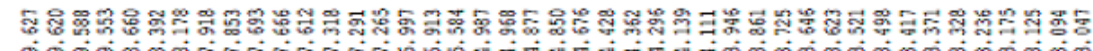

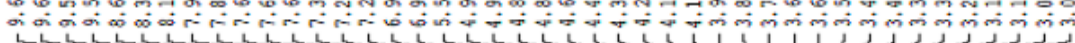

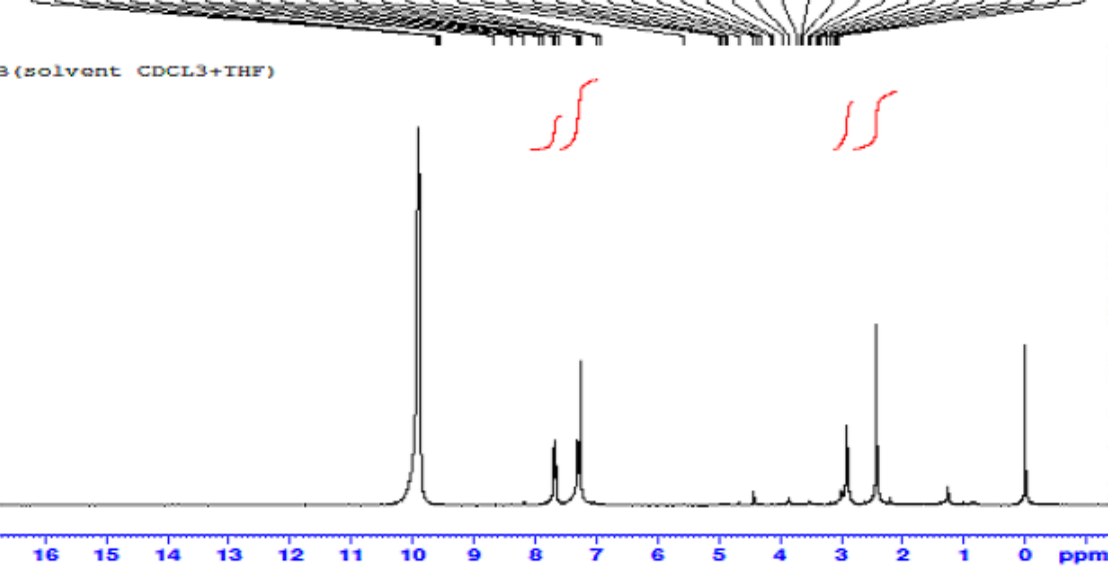

Fig. 2. (H-NMR) Spectrum of Compound(B)

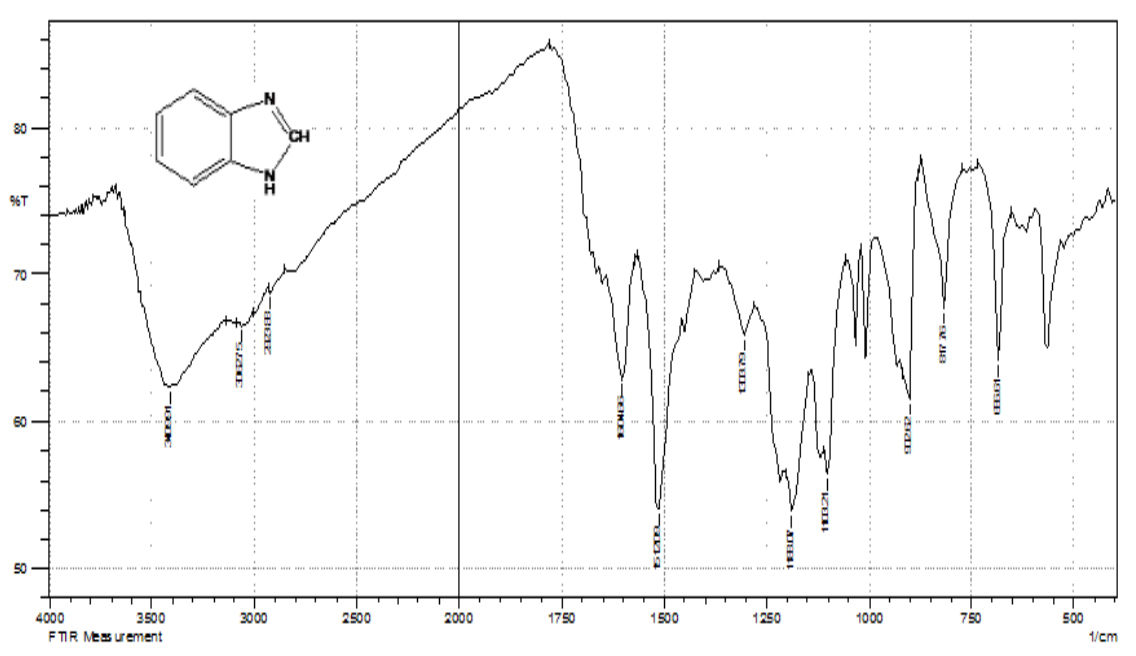

Fig. 3. (F.T.I.R) Spectrum of Compound(C)
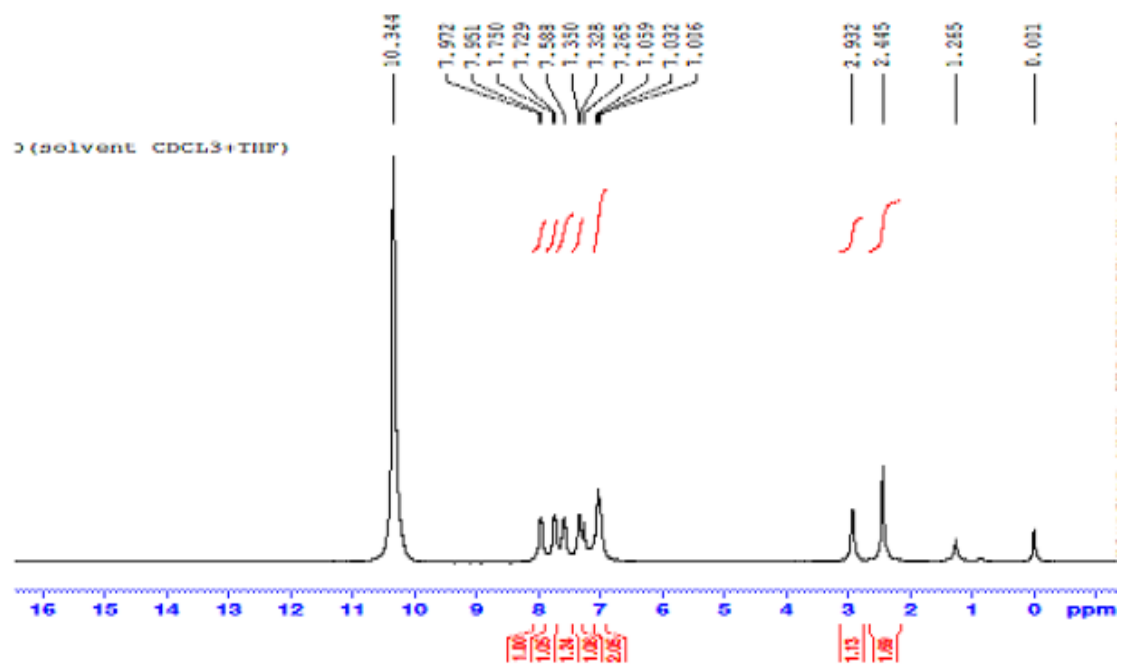

Fig. 4. (F.T.I.R) Spectrum of Compound(D) 


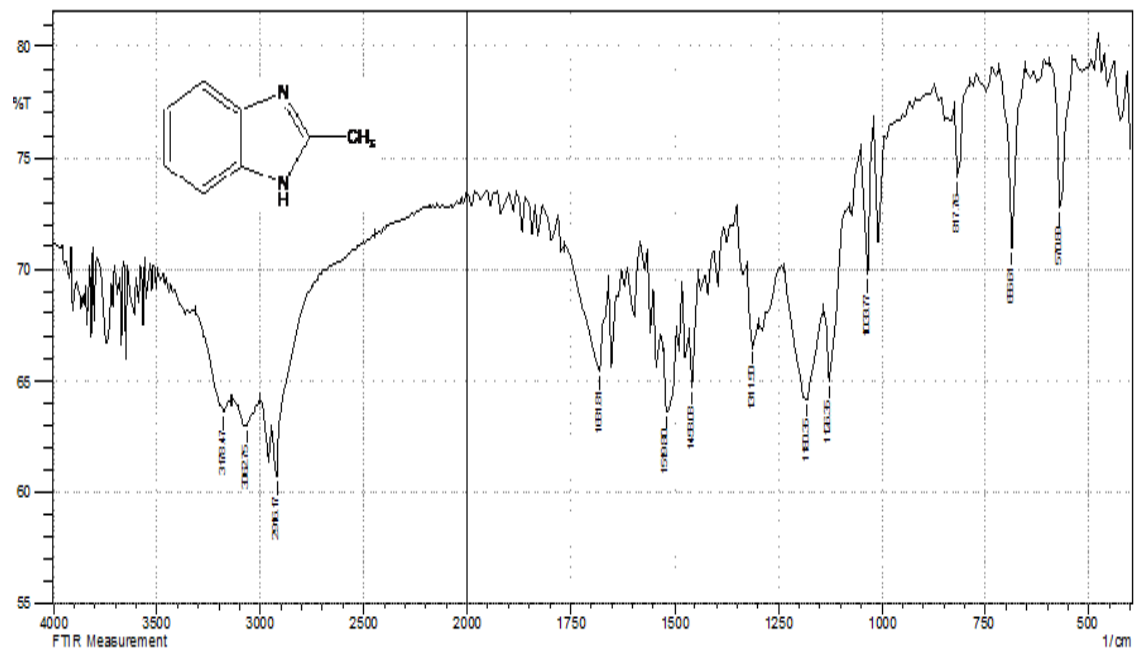

Fig. 5. (F.T.I.R) Spectrum of Compound(E)

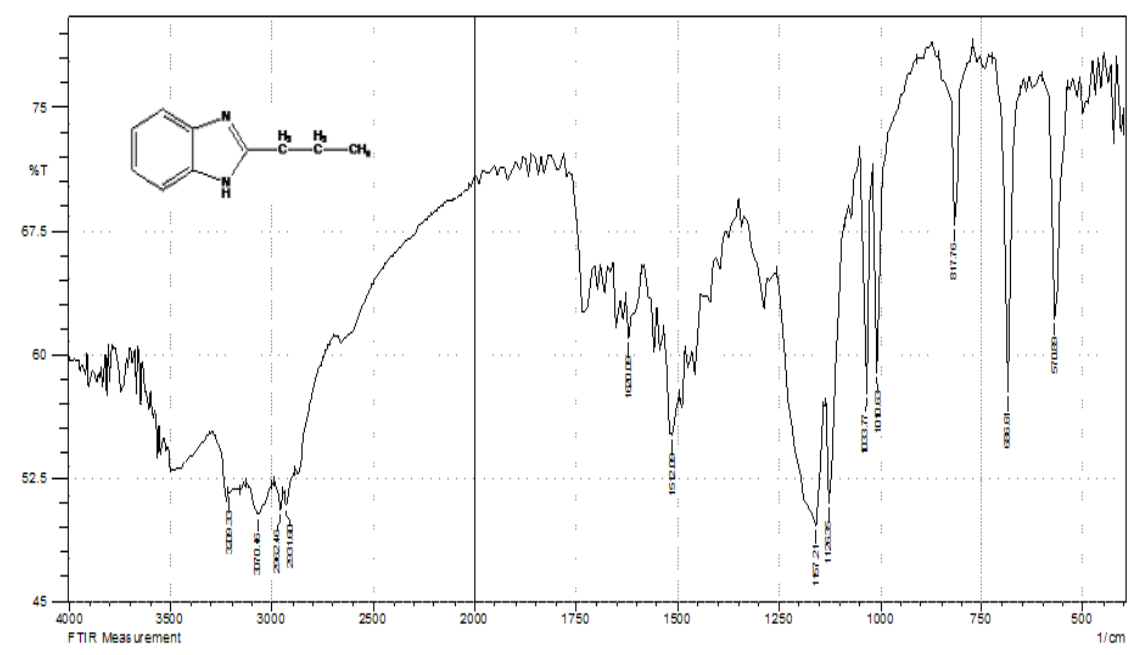

Fig. 6. (F.T.I.R) Spectrum of Compound (F)

Table 2: Absorption Peeks of Compounds in F.T.I.R. Spectroscopy

\begin{tabular}{|c|c|c|c|c|c|}
\hline Compounds & Name of compound & UV (nm) & $\begin{array}{c}(\mathrm{C}-\mathrm{H}) \text { aromatic } \\
\mathrm{cm}^{-1}\end{array}$ & $(C=N)(C=C)$ & $(\mathrm{C}-\mathrm{N})$ \\
\hline \multirow[t]{2}{*}{$A$} & 2-(4-Chlorophenyl) - & 318 & 3062 & $1512-1604$ & 1311 \\
\hline & 1H-Benzimidazole & 379 & & & \\
\hline \multirow[t]{3}{*}{ B } & 2-(4-N,N- Dimethylaniline) & & & & \\
\hline & -1H-Benzimidazole & 293 & 3039 & $1496-1604$ & 1365 \\
\hline & & 374 & & & \\
\hline $\mathrm{C}$ & 1H-Benzimidazle & 316 & 3062 & $1512-1604$ & 1303 \\
\hline \multirow[t]{3}{*}{$\mathrm{D}$} & 2-(2-Hydroxy Phenyl)- & & & & \\
\hline & 1H-Benzimidazole & 293 & 3024 & $1666-1612$ & 1249 \\
\hline & & 396 & & & \\
\hline$E$ & 2-Methyl-1H-Benzimidazole & 357 & 3062 & $1519-1681$ & 1311 \\
\hline $\mathrm{F}$ & 2-Propyl-1H-Benzimidazole & 357 & 3070 & $1512-1620$ & 1157 \\
\hline
\end{tabular}




\section{CONCLUSION}

In this study, a number of rings of benzimidazole have been synthesized from the reaction of o-phenylenediamine with different aldehydes and different carboxylic acids by using $\rho-\mathrm{T}_{s} \mathrm{OH}$ as a catalyst in all synthesis processes. The synthesis results have given a high percentage of the products with different solvent used. The spectral techniques FT.I.R and H-NMR have been used to diagnose the prepared rings.

\section{ACKNOWLEDGMENT}

The authors gratefully acknowledges Chemistry department, University of Al-Qadisiyah, Iraq for providing lab facilities to carry out this work.

\section{REFERENCE}

1. Mohanraj, V.; Murugesan, V.; Karthik, A.; Aravindan, B. J. Env. Nanote., 2014, 3(1) 48-52.

2. Xiangming, Han; Huiqiang, Ma; Yulu, Wang. ARKIVOC., 2007, (xiii), 150-154.

3. Quiroga, Jairo; Nogueras, Manuel; Cobo, Justo. Europ. J. of Medi. Chem., 2011, 46, 4062-4070.

4. Chaturvedi, Amit K.; Negi, Arvind S.; Khare, Puja. RSC Advances., 2013, 3, 4500-4504.

5. Pasha, Mohamed Afzal; Nizam, Aatika. J. of Saud. Chem. Soc., 2011, 15, 55-58.

6. Mungra, Divyesh C.; Patel, Manish P.; Patel,
Ranjan G. Med Chem Res., 2011, 20, 782-789.

7. Naeimi, Hossein; Alishahi, Nasrin. J. of Experi. Nanosc., 2013, DOI:10.1080/17458080.201 3.822575

8. Tarpada, Umesh P.; Thummar, Bhautik B.; Dipak, K. Raval. J. of Saud. Chem. Soci., 2016 20, 530-535.

9. Kadhim, Abdullah Jawad. Orient. J. of Chem., 2018, 34(1), 473-481

10. Dawood, Kamal M.; Abdel-Wahab, Bakr F. ARKIVOC. 2010, (I), 333-389. 